\title{
Effect of Low-Level Laser Therapy after Dental Extraction on Post-Operative Complications in Controlled Diabetic Patients
}

ISSN: 2637-7764

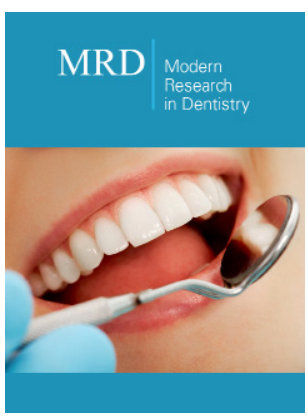

*Corresponding author: Alaa Makki, Oral and Maxillofacial Surgery Department, Faculty of Dental Medicine, Umm Al-qura University, Makkah 24225, Saudi Arabia

\section{Submission: 师 May 26, 2021}

Published: 㭰June 28, 2021

Volume 6 - Issue 4

How to cite this article: Alaa Makki Saad Alqarni, Mohammed Befle, et al. Effect of Low-Level Laser Therapy after Dental Extraction on Post-Operative Complications in Controlled Diabetic Patients. Mod Res Dent. 6(4). MRD. 000641. 2021.

DOI: 10.31031/MRD.2021.06.000641

Copyright@ Alaa Makki, This article is distributed under the terms of the Creative Commons Attribution 4.0 International License, which permits unrestricted use and redistribution provided that the original author and source are credited.

\author{
Alaa Makki ${ }^{*}$, Saad Alqarni ${ }^{2}$, Mohammed Befle ${ }^{2}$, Tariq Malyani ${ }^{2}$, Bassam Jambi ${ }^{2}$ \\ and Hashim Alshinkity ${ }^{2}$ \\ ${ }^{1}$ Oral and Maxillofacial Surgery Department, Faculty of Dental Medicine, Umm Al-qura \\ University, Makkah 24225, Saudi Arabia \\ ${ }^{2}$ Dental and Oral Surgery, Umm Al-qura University, Makkah 24225, Saudi Arabia
}

\begin{abstract}
Objective: The aim of this study is to evaluate the Effect of Low-Level Laser therapy after dental extraction on post-operative complications in controlled diabetic patients.

Material and Method: Prospective study was conducted in Oral Maxillofacial Surgery Clinic, Faculty of Dentistry, Umm Al-Qura University, Makkah, KSA. Thirty controlled diabetic patients with non-restorable teeth indicated for extraction were included in the study. The exclusion criteria; uncontrolled systemic disease, poor oral hygiene, smoker patient, blood disorders, any contraindications for laser therapy and patients whom taking analgesics in the past 24 hours before surgery.
\end{abstract}

Methods of assessments: Size of the alveolus was measured after extraction bucco-lingually and mesiodistally in millimeters immediately after laser application in study side, and for the controlled side we measured it after extraction only using periodontal prob. The pain was evaluated by visual analog scale (VAS). The scores extended between 0 (no pain) and 10 (the greatest pain). The pain was evaluated 8 hours after extraction and on the $7^{\text {th }}$ day. The swelling and redness were evaluated both the study and controlled sides by palpation and inspection respectively on $7^{\text {th }}$ day. The data was collected, tabulated and analyzed statistically using Statistical Package of social sciences software (SPSS).

A total of 30 patients participated in this study ( $M=47.20 \mathrm{y})$. Table 1 shows the descriptive data for the participants. For swelling and redness, there was no significant difference between the two groups after the $7^{\text {th }}$ postoperatively $(\mathrm{p}>0.05$; Table 2$)$.

Table 1: Descriptive Statistics.

\begin{tabular}{|c|c|c|c|c|c|}
\hline \multirow{2}{*}{ Age (years) } & $\mathbf{N}$ & Mean & Std. Deviation & Minimum & Maximum \\
\cline { 2 - 6 } & $\mathbf{3 0}$ & $\mathbf{4 7 . 2}$ & $\mathbf{1 3 . 1 2}$ & $\mathbf{2 5}$ & $\mathbf{7 0}$ \\
\hline $\begin{array}{c}\text { Blood glucose } \\
\text { (mg/dL) }\end{array}$ & 30 & 157.13 & 20.38 & 114 & 198 \\
\hline HbA1c & 30 & 6.6 & 0.71 & 5 & 7.5 \\
\hline
\end{tabular}

Table 2: Comparison of Swelling and Redness between Laser Treated and Control.

\begin{tabular}{|c|c|c|c|c|c|}
\hline & \multicolumn{3}{|c|}{ Swelling and Redness } & \multirow{2}{*}{ Pearson Chi-Square } & \multirow{2}{*}{ P value } \\
\hline Groups & Present & Absent & Total & & \multirow{2}{*}{0.028} \\
\hline Laser Treated & $3(10 \%)$ & $27(90 \%)$ & $30(100 \%)$ & \multirow{2}{*}{4.812} & \\
\hline Control & $10(33 \%)$ & $20(67 \%)$ & $30(100 \%)$ & & \\
\hline
\end{tabular}

Extraction site treated with LLLt showed decrease in the B-L width of the alveolus on the $7^{\text {th }}$ day after extraction; however, it was a statistically non-significant ( $p>0.05$; Table 3). And for the M-D width of the alveolus there was no significant difference between the $1^{\text {st }}$ day and the $7^{\text {th }}$ day $(p>0.05$; Table 3$)$. There was no significant difference in pain intensity in both sides after 8 hours from the extraction $(p>0.05$; Table 3). However, pain intensity in study side on the $7^{\text {th }}$ day was statistically non-significant $(p>0.05$; Table 3). 
Table 3: Comparison of effect of low-level laser therapy on healing after dental extraction between two groups.

\begin{tabular}{|c|c|c|c|c|c|c|c|c|}
\hline \multirow[b]{2}{*}{ Variables } & \multirow[b]{2}{*}{ Groups } & \multirow[b]{2}{*}{ Mean } & \multirow[b]{2}{*}{ SD } & \multirow[b]{2}{*}{ Std. Error Mean } & \multicolumn{2}{|c|}{$\begin{array}{l}\text { Differences Without } \\
\text { Controlling for } \\
\text { Covariates }\end{array}$} & \multicolumn{2}{|c|}{$\begin{array}{l}\text { Differences After } \\
\text { Controlling for } \\
\text { Covariates }\end{array}$} \\
\hline & & & & & $T$ value & $P$ value & $\mathbf{F}$ & $P$ value \\
\hline \multirow{2}{*}{$\begin{array}{l}\text { Baseline } \\
\text { B-L width }\end{array}$} & $\begin{array}{l}\text { Laser } \\
\text { Treated }\end{array}$ & 6.89 & 1.88 & 0.343 & 0.513 & 0.61 & 0.518 & 0.723 \\
\hline & Control & 6.63 & 2.09 & 0.382 & & & & \\
\hline \multirow{2}{*}{$\begin{array}{l}\text { Baseline } \\
\text { M-D } \\
\text { width }\end{array}$} & $\begin{array}{c}\text { Laser } \\
\text { Treated }\end{array}$ & 6.01 & 1.72 & 0.314 & 0.889 & 0.378 & 0.355 & 0.84 \\
\hline & Control & 5.59 & 1.96 & 0.358 & & & & \\
\hline \multirow{2}{*}{$\begin{array}{l}\text { B-L width } \\
\text { after } 7 \\
\text { days }\end{array}$} & $\begin{array}{l}\text { Laser } \\
\text { Treated }\end{array}$ & 3.23 & 1.98 & 0.361 & 0.203 & 0.84 & 0.946 & 0.444 \\
\hline & Control & 3.13 & 1.83 & 0.335 & & & & \\
\hline \multirow{2}{*}{$\begin{array}{l}\text { M-D } \\
\text { width } \\
\text { after } 7 \\
\text { days }\end{array}$} & $\begin{array}{l}\text { Laser } \\
\text { Treated }\end{array}$ & 2.97 & 1.71 & 0.313 & 0.304 & 0.762 & 0.53 & 0.714 \\
\hline & Control & 2.83 & 1.68 & 0.307 & & & & \\
\hline \multirow{2}{*}{$\begin{array}{l}\text { Pain after } \\
8 \text { hours }\end{array}$} & $\begin{array}{l}\text { Laser } \\
\text { Treated }\end{array}$ & 4.5 & 2.1 & 0.383 & 0.625 & 0.535 & 0.866 & 0.49 \\
\hline & Control & 4.17 & 2.04 & 0.372 & & & & \\
\hline \multirow{2}{*}{$\begin{array}{l}\text { Pain after } \\
7 \text { days }\end{array}$} & $\begin{array}{c}\text { Laser } \\
\text { Treated }\end{array}$ & 1.4 & 1.65 & 0.302 & -0.711 & 0.48 & 1.112 & 0.36 \\
\hline & Control & 1.73 & 1.96 & 0.359 & & & & \\
\hline
\end{tabular}

Conclusion: In conclusion, the LLLT showed no significant differences in the mean of controlling the post-operative complications after extraction between the study and controlled sides. So, using LLLt has no clinical significance after extraction among the controlled diabetic patient.

Keywords: Low level laser therapy; Dental extraction; Diabetic patients; Wound healing; Pain

\section{Introduction}

Within the field of medicine, surgical lasers have been used to manage several diseases such as rheumatoid arthritis, osteoarthritis, carpal tunnel syndrome, non-healing ulcers, epicondylitis and lumbago [1,2] (Silveira et al. 2011). Laser can be classified according to the energy level that is produced by the laser, which results in very different therapeutic actions. There are two primary levels: high-level laser therapy (HLLt), which is used mostly for surgical procedures; and low-level laser therapy (LLLt), which improves wound healing [3].

LLLt was discovered by the physician Mester when he accidentally noticed an increase and improvement in the healing process when attempting to stop cancer growth in mice [2]. Since then, the laser has also been introduced to dentistry as a treatment modality. Several examples include: frenectomy, temporomandibular diseases and to decrease postoperative complications after lower $3^{\text {rd }}$ molar extractions [4] (Peimani et al. 2018) (Sampaio-Filho et al. 2018). LLLt with a wavelength range between $300-400 \mathrm{mw}-\mathrm{cm} 2$ improves healing by fibroblast proliferation especially in diabetic patients [5]. On the other hand, the exact analgesic effect of LLLt is still unclear. However, there is an evidence suggested that LLLt plays a role in the synthesis, release, and metabolism of some neurotransmitters, such as an increase in serotonin and acetylcholine production in the central nervous system. In the peripheral nervous system, LLLt acts on some mediators of inflammation such as histamine and prostaglandin [6] (Sun \& Tunér 2004).

The effect of LLLt on postoperative pain is controversial, studies showed a significant relief of postoperative pain with a gallium aluminum arsenide diode laser (GaAlAs) of $810 \mathrm{~nm}, 0.1 \mathrm{~W}$ used intraorally with a dose of 23.86J/cm [7]. Moreover, the use of LLLt at $810 \mathrm{~nm}$ with a $4 \mathrm{j} / \mathrm{cm} 2$ energy density with $0.30 \mathrm{~W}$ output power showed a significant reduction of pain on the $7^{\text {th }}$ day postoperatively [8]. In comparison, there was no significance in the use of LLLt at $810 \mathrm{~nm}$ WL, $0.5 \mathrm{~W}$ output power, and $5 \mathrm{j} / \mathrm{cm} 2$ of energy density for 32 seconds intraorally $1 \mathrm{~cm}$ away from the target area [9].

Data regarding pain control and management of postoperative complications after routine dental extraction in diabetic patients after the application of the LLLt not clear. Hence this study aimed to evaluate the effect of low-level laser therapy after dental extraction on postoperative complications in controlled diabetic patients.

\section{Material and Methods}

A Quasi-Experimental split-mouth study conducted at the Oral Maxillofacial Surgery Clinic, Faculty of Dentistry, Umm AlQura University, Makkah, KSA. Ethical approval was obtained from 
the Research Committee of Faculty of Dentistry, Umm Al-Qura University with Institutional Review Board (IRB code: study no114-18). Thirty controlled diabetic patients with hopeless teeth were included in the study. Informed consent was discussed and signed. Uncontrolled diabetic patients, poor oral hygiene, smoker, blood disorders, any contraindications for laser therapy, and patients taking analgesics in the past 24 hours before surgery was excluded.

Local anesthesia with $1.7 \mathrm{ml}$ of $4 \%$ articaine hydrochloride with epinephrine 1/100,000 (Septanest $\mathrm{SP}^{\circledR}$ Novocol Pharmaceutical of Canada, Ontario, Canada) were used for anesthesia. Twenty minutes after extraction, a single application of $660 \mathrm{~nm}$ aluminum gallium arsenide (GaAlAs) diode laser (Laser $\mathrm{HF}^{\circledR}$ "Comfor Hager Weken, Germany) was applied for 80 seconds using a $200 \mathrm{~mm}$ in diameter fiber tip with continuous mode, $100 \mathrm{~mW}$ output power intraorally at a distance of $1 \mathrm{~cm}$ from the surgical area.

\section{Clinical assessments}

The size of the alveolus was measured after extraction Buccolingually (B-L) and Mesio-distally (M-D). Evaluation of pain was done on a visual analog scale (VAS) by asking the patient to report their pain threshold. The scores ranged between 0 (no pain) and 10 (greatest pain) (Figures $1 \& 2$ ). Patients instructed how to measure the pain by themselves with VAS. Pain was evaluated 8 hours after extraction and one week after extraction and laser application. Swelling and redness were evaluated both during the study and on the controlled sides by palpation and inspection respectively on the $7^{\text {th }}$ day (Figures $3 \& 4$ ).

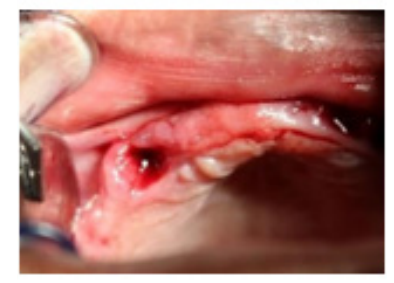

Figure 1: Controlled side on 1st day.

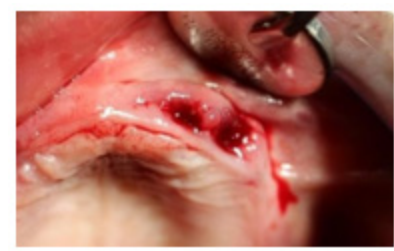

Figure 2: After laser application.

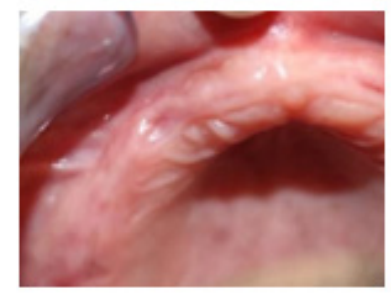

Figure 3: Controlled side on $7^{\text {th }}$ day.

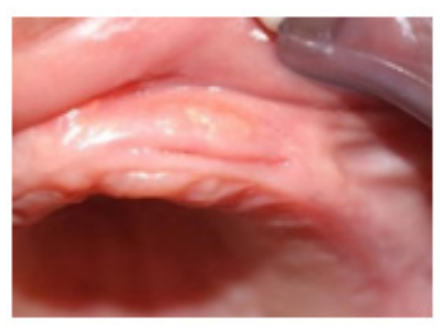

Figure 4: Study side in $7^{\text {th }}$ day.

\section{Statistical analysis and data management}

All date recorded on Microsoft Excel sheet and transferred to SPSS version 23 for statistical analysis. An independent biostatistician, who was not aware of the group allocation carried out the analysis. Data were normally distributed (Shapiro-Wilk Test, $\mathrm{p}=0.299$ ). Descriptive statistics were used in the form of means and standard deviation. Independent t-test used to compare the differences in the values between two groups. We used ANCOVA to determine the effect of covariates in the intervention. Pearson's Chi-square test was used to see the association of any categorical variables. A significance value, $\mathrm{p}<0.05$ was considered statistically significant.

\section{Result}

Study consisted of 30 patients who had undergone extraction of hopeless teeth at two sites. The mean age of our study participants was $47.2 \pm 3.12$ years. In each patient, one extraction site was treated with a single application of laser (LT), while the other site was left as a control group (C). The mean Bucco-lingual (BL) width of the LT site after 7 days was found to be $3.23 \pm 1.98 \mathrm{~mm}$ and there were no statistically significant differences observed with that of the control site $(\mathrm{p}=0.840)$.

The mean M-D width of the alveolus at the LT extraction site after 7 days was found to be $2.97 \pm 1.71 \mathrm{~mm}$ and that of the control site was $2.83 \pm 1.68 \mathrm{~mm}$, which also showed no statistically significant difference $(p=0.762)$. Prior to laser therapy treatment, there was no significant difference in all the patient variables between the two groups. The mean change in B-L width after 7 days in the LT group was $3.66 \pm 1.36 \mathrm{~mm}$ and in the control group it was $3.50 \pm 1.50 \mathrm{~mm}$. The M-D width in the LT group was $3.50 \pm 1.50 \mathrm{~mm}$ and in the control group it was $2.75 \pm 1.44 \mathrm{~mm}$.

In the clinical examination for pain, the patient was asked to score on a visual analogue scale (VAS), starting with $0 \mathrm{~cm}$ (no pain) to $10 \mathrm{~cm}$ (worst pain). Pain was also evaluated after 8 hours and 7 days for both the LT and control sites, respectively. In the LT group the mean VAS score after 8 hours was $4.50 \pm 2.10 \mathrm{~cm}$, whereas in the control group it was $4.17 \pm 2.04 \mathrm{~cm}$, indicating no statistically significant difference ( $\mathrm{p}=0.535)$. After 7 days the mean score of pain in the LT group was less $(1.40 \pm 1.65 \mathrm{~cm})$ compared to the control group $(1.73 \pm 1.96 \mathrm{~cm})$, but there was no statistically significant difference noted $(\mathrm{p}=0.480)$.

Analysis of covariance (ANCOVA) was used to see the effect of three covariates such as age ( $\leq 45$ years/ $>45$ years), blood sugar 
levels $(\leq 140 \mathrm{mg} / \mathrm{dL} />140 \mathrm{mg} / \mathrm{dL})$ and $\mathrm{HbA} 1 \mathrm{c}$ value $(\leq 6.5 \% />6.5 \%)$. Even after controlling for covariates there were no significant differences seen in B-L, M-D widths and pain scores (Table 3).

\section{Discussion}

This study utilized a split-mouth design in controlled diabetic patients to study the effect of laser treatment on alveolus healing and pain at the extraction site. After extraction, the tooth socket undergoes resorption and remodeling, and this process results in changes in height and width of the alveolar ridge (Zhao et al. 2011). In the field of surgery, gallium-arsenide (GaAs) and helium-neon (HeNe) lasers are the commonly used to enhance wound healing (Silveira et al. 2011). In dentistry, CO2, Nd:YAG, GaAlAs, and HF have been used to promote socket healing and pain modulation in tooth extraction sites $[10,11]$. Our study found no significant differences in B-L and M-D width of the alveolar socket between LT and control sites.

A study conducted by Batinjan et al. [12] showed that LLLT produced a significant reduction in postoperative wound swelling and decrease in wound temperature after surgical removal of third molars. The exact mechanism of how LLLt acts on biological tissues to promote wound healing, bone remineralization and pain control is not clearly identified. This could be due to the contradictory findings obtained from research conducted in animals [13] and humans $[3,14,15]$. A possible explanation for this healing process could be that laser may have an enhancing effect on proliferation of fibroblasts, osteoblasts and epithelial cells $[13,16,17]$.

This Study included controlled type 2DM patients to observe the effect of LLLt in wound healing and pain modulation. Type 2 DM patients often have macrovascular and microvascular complications, in which the later type is found to have a dramatic role in wound healing following tooth extraction $[18,19]$. In DM patients, the normal functioning of this microvasculation is compromised and this could have an effect in wound healing [19]. In our study, the LLLt applied may not have produced an additional stimulating effect on wound healing from the normal methods due to the underlying micro and macro vascular complications in these DM patients even though it was controlled. Research shows that inhibiting Interleukin-1 $\beta$ (IL-1 $\beta$ ) in the pro-inflammatory pathway increased wound healing in diabetic patients [20], Pradhan et al. 2011. Another split-mouth study reported that LLLt therapy had an inhibitory effect on IL-1 $\beta$ and IL- 6 after seven days of tooth extraction compared to the control site [14].

Our study found that pain after tooth extraction didn't show a statistically significant difference between LT and control group after 8 hours and 7 days. A study conducted in the United Arab Emirates, reported that there was significant reduction in pain after tooth extraction in a laser group (GaAlAs /810nm) compared to control group [7]. A study conducted by Kucerova et al. [15] reported that even though there was no difference observed in wound healing between laser treated group (helium-neon/638nm) and control group, there was a significant improvement in pain relief. Although numerous studies [1,21-23] have shown LLLt reduced postoperative pain after tooth extraction, it should be well noted that none of the studies used a split-mouth design as in our study. Also, a systematic review and meta-analysis conducted by Brignardello-Petersen et al. [24] reported that adjuvant LLLt didn't have a beneficial effect on pain and swelling after surgical removal of third molars.

The strength of our study was that this was the first split-mouth study done among controlled diabetic patients to determine the effect of LLLt in wound healing and pain relief. Accordingly, each patient served as their own control, eliminating the possibility of any bias in interventional effect and increasing the power of the study. We also analyzed the effect of covariates such as age, blood glucose levels and HbA1c values, which also showed no statistically significant effect on all the variables tested. Even though the findings of our study show that LLLt didn't produce a beneficial effect in wound healing and pain relief among diabetic patients, it is necessary to do a wider study with larger samples and use multiple wavelengths of LLLt with a multicenter design. In conclusion our study found that there was no significant difference in the size of alveolus between laser-treated and control sites in controlled diabetic patients. LLLt therapy may or may not have an effect on wound healing and pain relief in diabetic patients and the current evidence is insufficient to arrive at a conclusive statement. A well-designed randomized control trial on a larger sample in a multicenter environment is warranted.

\section{References}

1. Ferrante M, Petrini M, Trentini P, Perfetti G, Spoto G (2013) Effect of low-level laser therapy after extraction of impacted lower third molars. Lasers Med Sci 28(3): 845-849.

2. Mester E, Spiry T, Szende B, Tota JG (1971) Effect of laser rays on wound healing. Am J Surg 122(4): 532-535.

3. Fernando S, Hill C, Walker R (1993) A randomised double blind comparative study of low level laser therapy following surgical extraction of lower third molar teeth. Br J Oral Maxillofac Surg 31(3): 170-172.

4. Haytac MC, Ozcelik O (2006) Evaluation of patient perceptions after frenectomy operations: a comparison of carbon dioxide laser and scalpel techniques. J Periodontol 77(11): 1815-1819.

5. Hansen HJ, Thorøe U (1990) Low power laser biostimulation of chronic oro-facial pain. A double-blind placebo controlled cross-over study in 40 patients. Pain 43(2): 169-179.

6. Hagiwara S, Iwasaka H, Okuda K, Noguchi T (2007) GaAlAs (830nm) low-level laser enhances peripheral endogenous opioid analgesia in rats. Lasers Surg Med 39(10): 797-802.

7. Hamid MA (2017) Low-level laser therapy on postoperative pain after mandibular third molar surgery. Ann Maxillofac Surg 7(2): 207-216.

8. Koparal M, Ozcan Kucuk A, Alan H, Asutay F, Avci M (2018) Effects of lowlevel laser therapy following surgical extraction of the lower third molar with objective measurement of swelling using a three-dimensional system. Exp Ther Med 15(4): 3820-3826.

9. López Ramírez M, Vílchez Pérez MÁ, Gargallo Albiol J, Arnabat Domínguez J, Gay Escoda C (2012) Efficacy of low-level laser therapy in the management of pain, facial swelling, and postoperative trismus after a lower third molar extraction. A preliminary study. Lasers Med Sci 27(3): 559-566.

10. Fukuoka H, Daigo Y, Enoki N, Taniguchi K, Sato H (2011) Influence of carbon dioxide laser irradiation on the healing process of extraction sockets. Acta odontol Scand 69(1): 33-40. 
11. Mergoni G, Vescovi P, Sala R, Merigo E, Passerini P, et al. (2016) The effect of laser therapy on the expression of osteocalcin and osteopontin after tooth extraction in rats treated with zoledronate and dexamethasone. Support Care Cancer 24(2): 807-813.

12. Batinjan G, Zore Z, Čelebić A, Papić M, Gabrić Pandurić D, et al. (2014) Thermographic monitoring of wound healing and oral health-related quality of life in patients treated with laser (aPDT) after impacted mandibular third molar removal. International Journal of Oral and Maxillofacial Surgery 43(12): 1503-1508.

13. Hirata S, Kitamura C, Fukushima H, Nakamichi I, Abiko Y, et al (2010) Low-level laser irradiation enhances BMP-induced osteoblast differentiation by stimulating the BMP/Smad signaling pathway. J Cell Biochem 111(6): 1445-1452.

14. Mozzati M, Martinasso G, Cocero N, Pol R, Maggiora M, et al. (2011) Influence of superpulsed laser therapy on healing processes following tooth extraction. Photomed Laser Surg 29(8): 565-571.

15. Kucerová H, Dostálová T, Himmlova L, Bártová J, Mazánek J (2000) Lowlevel laser therapy after molar extraction. J Clin Laser Med Surg 18(6): 309-315.

16. Fujihara NA, Hiraki KR, Marques MM (2006) Irradiation at $780 \mathrm{~nm}$ increases proliferation rate of osteoblasts independently of dexamethasone presence. Lasers Surg Med 38(4): 332-336.

17. Eduardo FP, Mehnert DU, Monezi TA, Zezell DM, Schubert MM, et al. (2007) Cultured epithelial cells response to phototherapy with low intensity laser. Lasers Surg Med 39(4): 365-372.
18. Ekmektzoglou KA, Zografos GC (2006) A concomitant review of the effects of diabetes mellitus and hypothyroidism in wound healing. World J Gastroenterology 12(17): 2721-2729.

19. Lioupis C (2005) Effects of diabetes mellitus on wound healing: an update. J Wound Care 14(2): 84-86.

20. Mirza RE, Fang MM, Ennis WJ, Koh TJ (2013) Blocking interleukin$1 \beta$ induces a healing-associated wound macrophage phenotype and improves healing in type 2 diabetes. Diabetes 62(7): 2579-2587.

21. Asutay F, Ozcan Kucuk A, Alan H, Koparal M (2018) Three-dimensional evaluation of the effect of low-level laser therapy on facial swelling after lower third molar surgery: A randomized, placebo-controlled study. Niger J Clin Pract 21(9): 1107-1113.

22. Hamzah BF, Ibraheem NS (2019) The effect of low-level laser therapy after simple tooth extraction. Journal of International Oral Health 11(4): 181-186.

23. El Soud N, El Shenawy H (2010) A randomized double blind clinical study on the efficacy of low-level laser therapy in reducing pain after simple third molar extraction. Macedonian Journal of Medical Sciences 3(3): 303-306.

24. Brignardello Petersen R, Carrasco Labra A, Araya I, Yanine N, Beyene J, et al. (2012) Is adjuvant laser therapy effective for preventing pain, swelling, and trismus after surgical removal of impacted mandibular third molars? A systematic review and meta-analysis. J Oral Maxillofac Surg 70(8): 1789-1801. 